\title{
Prenatal Diagnosis of Severe Mitochondrial Diseases Caused by Nuclear Gene Defects: A Study in Japan
}

\section{Nana Akiyama}

Chiba Children's Hospital

Masaru Shimura

Chiba Children's Hospital

Taro Yamazaki

Saitama Medical University: Saitama Ika Daigaku

Hiroko Harashima

Saitama Medical University: Saitama Ika Daigaku

Takuya Fushimi

Chiba Children's Hospital

Tomoko Tsuruoka

Chiba Children's Hospital

Tomohiro Ebihara

Chiba Children's Hospital

Keiko Ichimoto

China Children's Hospital

Ayako Matsunaga

Chiba Children's Hospital

Megumi Saito-Tsuruoka

Saitama Medical University: Saitama Ika Daigaku

Yukiko Yatsuka

Juntendo University: Juntendo Daigaku

Yoshihito Kishita

Juntendo University: Juntendo Daigaku

Masakazu Kohda

Juntendo University: Juntendo Daigaku

Akira Namba

Saitama Medical University: Saitama Ika Daigaku

Yoshimasa Kamei

Saitama Medical University: Saitama Ika Daigaku

Yasushi Okazaki

Juntendo University: Juntendo Daigaku

Shinji Kosugi

Kyoto University: Kyoto Daigaku

Akira Ohtake

Saitama Medical University: Saitama Ika Daigaku

Kei Murayama ( $\nabla$ kmuraya@mri.biglobe.ne.jp)

Department of Metabolism, Chiba Children's Hospital, 579-1 Heta-cho, Midori-ku, Chiba 266-0007, Japan https://orcid.org/0000-0002-3923-8636

\section{Research}

Keywords: Prenatal diagnosis, mitochondrial diseases, nuclear gene defect, severe phenotype, chorionic villus sampling, amniocentesis

Posted Date: October 21st, 2020

DOI: https://doi.org/10.21203/rs.3.rs-93961/v1

License: @ (i) This work is licensed under a Creative Commons Attribution 4.0 International License. Read Full License

Version of Record: A version of this preprint was published at Scientific Reports on February 11th, 2021. See the published version at https://doi.org/10.1038/s41598-021-81015-y. 


\section{Abstract}

Background: Prenatal diagnoses of mitochondrial diseases caused by defects in nuclear DNA (nDNA) or mitochondrial DNA (mtDNA) have been reported in several countries except for Japan. The present study aimed to clarify the status of prenatal genetic diagnosis of mitochondrial diseases caused by nDNA defects in Japan. A comprehensive genomic analysis was performed to diagnose more than 400 patients, of which, 13 families (18 cases) had requested prenatal diagnoses.

Results: Eight cases diagnosed with wild homozygous or heterozygous variants same as either of the heterozygous parents continued the pregnancy and delivered healthy babies. Another eight cases were diagnosed with homozygous, compound heterozygous, or hemizygous variants same as the proband. Of these, seven families chose to terminate the pregnancy, while one decided to continue the pregnancy.

Conclusions: Neonatal- or infantile-onset mitochondrial diseases show severe phenotypes and lead to lethality. Therefore, such diseases could be candidates for prenatal diagnosis with careful genetic counseling, and prenatal testing could be a viable option for families.

\section{Background}

Mitochondrial diseases have the highest incidence rate (1 in 5000 births) among all hereditary metabolic disorders. ${ }^{1}$ Mitochondria are primarily responsible for generating adenosine triphosphate by oxidative phosphorylation. Two distinct genomes can contribute to mitochondrial disease pathogenesis: the nuclear genome and the maternally inherited $16.6 \mathrm{~kb}$ mitochondrial genome. ${ }^{2,3}$ Mitochondrial diseases result from mutations in either of these genomes. Defects in nuclear DNA (nDNA) can cause problems such as defects in respiratory chain complex structure, translation, and mitochondrial DNA (mtDNA) maintenance and repair. ${ }^{3,4}$ Approximately $25 \%$ of the mitochondrial diseases diagnosed in childhood are due to mtDNA abnormalities, whereas the remaining $75 \%$ are due to nDNA defects. 5,6

Severe neonatal- or infantile-onset mitochondrial diseases usually result in death within the first year of life. ${ }^{5,6} \mathrm{~A}$ study reported that lethal infantile mitochondrial disease (LIMD) constitutes approximately $8.5 \%$ of the cases of childhood-onset mitochondrial diseases. ${ }^{6}$ Most cases of LIMD are diagnosed biochemically and genetically after the decease of subjects. Such cases of severe neonatal-onset mitochondrial diseases such as LIMD, Leigh syndrome, and mtDNA depletion syndrome may therefore serve as candidates for prenatal diagnosis, when the parents wish to conceive again.

Approximately 20,000 women in Japan undergo invasive prenatal genetic testing every year, ${ }^{7}$ and the most relevant reason is advanced maternal age. Prenatal diagnoses of mitochondrial diseases caused by nDNA or mtDNA defects are prevalent in several countries, ${ }^{8-10}$ but not in Japan. The Japan Society of Obstetrics and Gynecology issued guidelines for prenatal diagnosis of severe pediatric-onset diseases caused by chromosomal abnormalities or nDNA defects. However, there have been no guidelines for the diagnosis of mtDNA-associated diseases. ${ }^{11}$

The advent of next-generation sequencing has increased the diagnostic yield for mitochondrial diseases, concomitant with the increasing need for prenatal diagnosis. However, little information is available on genetic counseling for mitochondrial diseases, especially in Japan. Therefore, this study aimed to clarify the status of prenatal genetic diagnosis of mitochondrial diseases caused by nDNA defects in Japan.

\section{Results}

In this study, 16 prenatal diagnoses for 13 families were performed safely between August 2014 and January 2020. No complications occurred during the chorionic villus sampling (CVS) and amniocentesis (AC). The results of the prenatal diagnosis and details of the pregnancy course were as follows (Fig 1): Five cases were found to be carriers of autosomal recessive genes. Two cases were proven as wild type homozygous for BOLA3. As the chromosomal analysis in family (Fam) \#7-2 with the TAZ mutation showed the fetus was a female, we did not conduct further genetic analysis. In these eight cases, the parents decided to continue the pregnancy and gave birth to healthy children. The other eight cases were found to carry pathogenic variants in the compound heterozygous or hemizygous states. The parents of Fam \#8-1 decided to continue the pregnancy, while those of the remaining seven cases decided to terminate the pregnancies.

\section{Discussion}

In this study, we have shown a summary of prenatal diagnoses for mitochondrial diseases caused by nDNA mutations in Japanese patients. This is the first comprehensive study of prenatal diagnoses for mitochondrial diseases in Japan.

In our cohort, seven probands developed initial symptoms during the neonatal period ( $<1$ month). The other six probands developed initial symptoms during the infantile period ( $<1$ year). Moreover, among all cases, seven probands died before completing 1 year of age. Five families had BOLA3 mutations, and all the probands died. Among them, four (Fam \#1, \#2, \#3, and \#12) patients had homozygous c.287A>G, while one from Fam \#13 had compound heterozygous c. $287 \mathrm{~A}>\mathrm{G}$ with another mutation. Our previous report suggested that this variant is common in the Japanese population and originates from a single founder. ${ }^{14}$ Moreover, two probands had MPV17 mutations (Fam \#9 and \#11) and developed severe liver manifestations. MPV17 is the most common gene in hepatocerebral mitochondrial DNA depletion syndrome (MTDPS) in the Japanese population, and c.451dupC in MPV17 is a frequently occurring mutation. ${ }^{15} \mathrm{~A}$ homozygous c.451dupC mutation has also been identified in Korean siblings that died of liver failure at 6 months of age, and homozygosity is assumed to be associated with poor outcomes. ${ }^{15,16}$

As described in the indexed case profile, in Fam \#12, only the mother was a carrier for the pathogenic variant. The large deletion in or around $B O L A 3$ in his father was absent. BOLA3-associated mitochondrial diseases follow an autosomal recessive inheritance pattern. In some cases, only one parent is the carrier, 
and the mutation is segregated to the patient through uniparental isodisomy (UPiD). ${ }^{17}$ The maternal isodisomy of the whole chromosome 2 was confirmed using short nucleotide polymorphism experiments. Although we explained repeatedly that the recurrence risk is almost null in the case of UPiD, prenatal diagnosis was conducted upon strong requests by the parents.

During prenatal genetic counseling, parents and families consider the multiple options available and make a decision based on the impact of the tests on their lives and their future child in various ways. In our cohort, some families did not opt for prenatal diagnosis after considering the risks of villus and amniotic fluid tests. In addition, one family (Fam \#8) decided to give birth to an affected child after prenatal diagnosis. An important role of genetic counselors is to provide accurate information about tests and support the family's decisions. ${ }^{9,18}$ It is an immense challenge for the families to give birth to a child who would follow a severe fate after birth. Therefore, it is necessary to obtain the unified cooperation of obstetricians, neonatologists, pediatricians, and other healthcare providers. The samples for prenatal tests are obtained via CVS or/and AC. CVS and AC are usually performed at 11-14 and after 15 weeks of gestation, respectively. The spontaneous miscarriage rate is approximately $1 \%$ and $0.2-0.5 \%$ for CVS and AC, respectively. ${ }^{19}$ Wulff et al. reported that neither CVS nor AC have any significant effect on the risk of miscarriage or stillbirth. ${ }^{20}$ In our cohort, no spontaneous miscarriages occurred as a result of prenatal testing.

Prenatal diagnosis for mtDNA-related mitochondrial diseases is prevalent in several countries. ${ }^{8-10}$ Furthermore, preimplantation genetic testing for Leigh syndrome caused by mtDNA mutation has been reported in Japan. ${ }^{21}$ However, recent studies indicated that prenatal samples provide an accurate prediction

of mtDNA mutation load in the postnatal period. ${ }^{22}$ Nonetheless, the relationship between genotype and phenotype is far less clear with regard to some mtDNA mutations. Therefore, further research to ascertain the correlation between genotype, mutation load, and phenotype is required concerning such mtDNA mutations. Moreover, a recent study revealed that de novo mtDNA point mutations are common, and the recurrence risk is low. ${ }^{23}$ The Japan Society of Obstetrics and Gynecology guideline does not mention prenatal diagnosis of mtDNA-associated diseases. ${ }^{11}$ Therefore, careful consideration toward prenatal testing for mtDNA-associated diseases is needed.

This study provides a comprehensive account of the status of prenatal diagnosis of mitochondrial diseases caused by nuclear gene defects in Japan. As shown in our previous report, neonatal- or infantile-onset mitochondrial diseases exhibit an extremely severe phenotype. ${ }^{5}$ Furthermore, there are only few treatments available for such severe cases. Since the diagnostic ability of genetic tests for neonatal- or infantile-onset mitochondrial diseases is steadily increasing, ${ }^{24}$ it is presumed that the demand for prenatal diagnosis of neonatal-onset mitochondrial diseases will also increase. Further discussions and data collection are needed for a more effective application of prenatal testing of mitochondrial diseases caused by both nDNA and mtDNA defects.

\section{Conclusions}

Neonatal- or infantile-onset mitochondrial diseases often show severe phenotype and follow a lethal course. These diseases could be candidates for prenatal diagnosis, and prenatal testing should be considered as one of the important options for parents. Therefore, adequate and appropriate genetic counseling is required before and after prenatal testing.

\section{Methods}

\section{Molecular and genetic diagnoses of the index case}

First, the analyses of enzyme activities and oxygen consumption rates were performed for patients who were suspected to have mitochondrial diseases. Thereafter, whole mtDNA and whole exome sequencing and validation tests were performed. Genetic counseling before and after prenatal diagnosis, CVS, and AC were performed at the Department of Pediatrics and Department of Obstetrics and Gynecology, Saitama Medical University Hospital. The obtained samples were analyzed at Juntendo University.

\section{Prenatal diagnosis}

In total, 13 probands from 13 families were diagnosed with severe mitochondrial diseases caused by pathogenic variants in nDNA. Most of the probands had homozygous or compound heterozygous variants in the autosomal recessive genes (ACAD9 [MIM 611103] $(\mathrm{n}=1), B O L A 3$ [MIM 613183] ( $\mathrm{n}=5), E C H S 1$ [MIM 602292] ( $\mathrm{n}=1$ ), MPV17 [MIM 256810] ( $\mathrm{n}=2$ ), NDUFAF6 [MIM 612392] ( $\mathrm{n}=1)$, RARS2 [MIM 611524] $(\mathrm{n}=1)$, TUFM [MIM 602389] ( $\mathrm{n}=1)$ ). Only one proband had a hemizygous variant in the X chromosome-linked gene (TAZ [MIM 300394] $(n=1)$ ). The details of each family are described in the following section and Table 1. The 13 families (18 cases) decided to undergo prenatal diagnosis.

Among the 18 pregnancies, 2 resulted in early miscarriage. In the remaining 16 cases that reached the second trimester of pregnancy, 9 opted to have CVS, and 6 opted for AC. One case showed possible maternal cell contamination in the CVS sample and subsequently underwent AC. Each causative nuclear gene variant was confirmed by direct Sanger sequencing of PCR-amplified products.

\section{Index case profiles (Table 1, Fig 2)}

Family \#1 (Fig 2-a): Proband (II-1) was a female born at full term (birth weight of $3.10 \mathrm{~kg}$, within the normal range) as the first child to non-consanguineous healthy parents. She exhibited cardiomyopathy with lactic acidosis at 2 months of age, developed heart and liver failure, and died at 5 months of age. Genetic analysis revealed pathogenic variants in $B O L A 3$ (c.287A>G/c.287A $>\mathrm{G}$ ); additionally, both parents were heterozygous carriers of this variant.

Family \#2 (Fig 2-b): Proband (II-1) was a female born at full term (birth weight of 3.29 kg, within the normal range). She exhibited feeding difficulty at 24 days of age. Laboratory studies revealed severe lactic acidosis, hyperglycemia, and metabolic acidosis; as a result, she was admitted to an intensive care unit. 
Moreover, she manifested cardiomyopathy, apnea, epilepsy, and liver failure and died of heart failure at 7 months of age. Genetic analysis revealed that she harbored pathogenic variants in $B O L A 3$ (c.287A $>\mathrm{G} / \mathrm{c} .287 \mathrm{~A}>\mathrm{G}$ ), and both parents were heterozygous carriers of this variant.

Family \#3 (Fig 2-c): Proband (II-3) was a male born at full term. His elder brother died at 4 months of age, but details were not available. The proband developed lactic acidosis, hyperglycemia, and an elevated creatine kinase level at 17 days of age. He subsequently showed muscle weakness, hypotonia, and cardiomyopathy and died at 17 months of age. Genetic analysis identified pathogenic variants in $B O L A 3$ (c.287A>G/c.287A>G), and both parents were heterozygous carriers of this variant. Furthermore, he had homozygous variants in FKTN. The patient has been reported in a previous study. ${ }^{12}$

Family \#4 (Fig 2-d): Proband (II-2) was a female born at full term (birth weight of $2.55 \mathrm{~kg}$, within the normal range). Her elder sister, who had hypotonia with cardiomyopathy, died of acute bronchitis at 6 months of age. The proband was reported to have hypotonia at 5 months of age and exhibited lactic acidosis and hypertrophic cardiomyopathy. Thereafter, she died of acute myocarditis at 13 months of age. She had two different pathogenic variants in $A C A D 9$ (c.1766-2A>G/c.811T>G), and both parents were carriers of either of these variants.

Family \#5 (Fig 2-e): Proband (II-1) was a female born at full term (birth weight of $2.93 \mathrm{~kg}$, within the normal range). Regression and lactic acidosis appeared at 7 months of age. She was diagnosed with Leigh syndrome and died of respiratory failure at 5 years of age. Genetic analysis identified two different pathogenic variants in NDUFAF6 (c. $805 \mathrm{C}>\mathrm{G} / \mathrm{c} .226 \mathrm{~T}>\mathrm{C})$, and both parents were carriers of either of these variants.

Family \#6 (Fig 2-f): This family had two probands. Proband (II-1) was a male born at 34 weeks and 2 days (birth weight of 0.81 kg, -4.4 SD). On the first day, lactic acidosis and apnea were observed, and he died at 8 days of age. Proband (II-2) was the second male child born at 36 weeks and 6 days (birth weight of $1.06 \mathrm{~kg} ;-5.1 \mathrm{SD})$. He had congenital heart disease and aortic coarctation and ventricular septal defect. He died of multiple organ failure at 20 days of age. Genetic analysis identified two different pathogenic variants in TUFM (c.440T>A/c.162delC), and both parents were carriers of either of these variants.

Family \#7 (Fig 2-g): Proband (III-2) was a male born at full term (birth weight of $2.59 \mathrm{~kg}$; within the normal range). Five maternal cousins of his mother (II-5, II-6, II-7, II-8, and II-9) died in the fetal period or during early infancy. Detailed information about them was not available. Hypertrophic cardiomyopathy with cyanosis and respiratory failure occurred in the proband at 8 months of age. Genetic analysis identified a pathogenic variant in TAZ (X chromosome-linked gene) (c.367C>T), and his mother was a carrier of this variant.

Family \#8 (Fig 2-h): Proband (II-2) was a female born at 39 weeks of gestation (birth weight of 2.94 kg, within the normal range). Her elder sister died of respiratory failure with severe lactic acidosis at 1 day of age. The proband exhibited moderate lactic acidosis and hypotonia shortly after birth. Lactic acidosis was improved by medical treatment; however, she developed severe respiratory and cardiac failure resulting in death at 124 days of age. Metabolic profiling showed no abnormal findings. The brain magnetic resonance imaging at 8 days of age showed T2 high intensities in the cerebral white matter and diffuse brain atrophy at 58 days of age. An autopsy was performed after death. Genetic analysis identified two different pathogenic variants in ECHS1 $(c 176 \mathrm{~A}>\mathrm{G} / \mathrm{c} .476 \mathrm{~A}>\mathrm{G})$, and both parents were carriers of either of these variants.

Family \#9 (Fig 2-i): Proband (II-1) was a male born at full term (birth weight of $3.2 \mathrm{~kg}$, within the normal range). Poor weight gain and cholestasis were noticed at 1 month of age. The liver showed microvesicular steatosis with swollen hepatocytes and partial necrosis. His jaundice progressed and liver transplantation was performed at 11 months of age. He died of pulmonary hypertension at 2 years and 9 months of age. Genetic analysis identified pathogenic variant in MPV17 (c.451dupC/c.451dupC), and both parents were heterozygous carriers of this variant. The proband has been reported in a previous study ${ }^{13}$ (family 18 , subject 20).

Family \#10 (Fig 2-j): Proband (II-2) was a female born at full term (birth weight of $2.42 \mathrm{~kg}$, within the normal range). She exhibited cardiomyopathy with lactic acidosis at 2 days post birth. Thereafter, her cardiomyopathy progressed to heart failure, and liver failure occurred. Genetic analysis identified pathogenic variant in $R A R S 2$ (c. $944 \mathrm{G}>\mathrm{C} / \mathrm{c} .944 \mathrm{G}>\mathrm{C}$ ), and both parents were heterozygous carriers of this variant.

Family \#11 (Fig 2-k): Proband (II-1) was a male born at full term (birth weight of $2.69 \mathrm{~kg}$, within the normal range). He showed tachypnea due to respiratory distress syndrome shortly after birth and was treated with mechanical ventilation for 3 days. Hypotonia and poor weight gain was observed at 3 months of age. Laboratory examinations showed elevated levels of liver transaminases and direct bilirubin. He died of liver failure at 10 months of age. Genetic analysis identified two different pathogenic variants in MPV17(c.451dupC/c.308_310del), and both parents were carriers of either of these variants.

Family \#12 (Fig 1-I): Proband (II-1) was a male born at full term. He developed impaired consciousness and cardiomyopathy with lactic acidosis at 4 months of age. He died 15 days later. Genetic analysis identified pathogenic variant in $B O L A 3$ (c.287A>G/ c.287A>G), and his mother was a carrier of this variant.

Family \#13 (Fig 1-m): Proband (II-1) was a male born at full term (birth weight of $2.41 \mathrm{~kg}$, within the normal range). Regression appeared at 4 months of age. Additionally, he showed hypotonia and horizontal nystagmus. Symmetrical white matter lesions and lactate peaks were observed in the brain magnetic resonance imaging and magnetic resonance spectroscopy, respectively. Cardiomyopathy had developed and progressed rapidly, and he died at 6 months of age. Genetic analysis identified two different pathogenic variants in $B O L A 3$ (c.287A>G/ c.136C >T), and both parents were carriers of either of these variants.

\section{Declarations}

\section{Ethics approval and consent to participate}

Institutional review board/ethics committee at Saitama Medical University approved the protocol of prenatal diagnosis. All parents provided informed written consent prior to prenatal testing. .

\section{Consent for publication}


Written informed consent was obtained from the parents of all subjects included in the study.

\section{Availability of data and materials}

The datasets analyzed during the current study are available from the corresponding author on reasonable request.

\section{Competing interests}

The authors declare that they have no competing interests.

\section{Funding}

This work was supported by the Innovative Cell Biology grant by the Innovative Technology (Cell Innovation Program) from the Ministry of Education, Culture, Sports, Science, and Technology (MEXT), partly by the Practical Research Project for Rare/Intractable Diseases (JP20ek0109468 and JP19ek0109273) from the Agency for Medical Research and Development (AMED), Japan, and the Japanese Association for Medical Promotion of Mitochondrial Disease (JAMPMIT).

\section{Authors' Contributions}

YO, AO, and KM conceptualized and designed the project. NA, MS, and TY drafted the manuscript. HH, TT, TE, KI, AM, MST, and AN participated in data acquisition. TF, YY, YK, and MK analyzed and interpreted data. Yoshimasa Kamei and SK critically reviewed the manuscript. All authors read and approved the final manuscript.

\section{Acknowledgments}

The authors thank all the patients and their doctors in charge for providing us with the data.

\section{References}

1. Skladal D, Halliday J, Thorburn DR. Minimum birth prevalence of mitochondrial respiratory chain disorders in children. Brain. 2003;126:1905-12.

2. Taylor RW, Turnbull DM. Mitochondrial DNA mutations in human disease. Nat Rev Genet. 2005;6:389-402.

3. Schon EA, DiMauro S, Hirano M. Human mitochondrial DNA: roles of inherited and somatic mutations. Nat Rev Genet. 2012;13:878-90.

4. Battersby BJ, Loredo-Osti JC, Shoubridge EA. Nuclear genetic control of mitochondrial DNA segregation. Nat Genet. 2003;33:183-6.

5. Ohtake A, Murayama K, Mori M, Harashima H, Yamazaki T, Tamaru S, et al. Diagnosis and molecular basis of mitochondrial respiratory chain disorders: exome sequencing for disease gene identification. Biochim Biophys Acta. 2014;1840:1355-9.

6. Murayama K, Shimura M, Liu Z, Okazaki Y, Ohtake A. Recent topics: the diagnosis, molecular genesis, and treatment of mitochondrial diseases. J Hum Genet. 2019;64:113-25.

7. Sasaki A, Sawai H, Masuzaki H, Hirahara F, Sago H. Low prevalence of genetic prenatal diagnosis in Japan. Prenat Diagn. 2011;31:1007-9.

8. Nesbitt V, Alston CL, Blakely EL, Fratter C, Feeney CL, Poulton J, et al. A national perspective on prenatal testing for mitochondrial disease. Eur J Hum Genet. 2014;22:1255-9.

9. Thorburn DR, Dahl HH. Mitochondrial disorders: genetics, counseling, prenatal diagnosis and reproductive options. Am J Med Genet. 2001;106:102-14.

10. White SL, Collins VR, Wolfe R, Cleary MA, Shanske S, DiMauro S, et al. Genetic counseling and prenatal diagnosis for the mitochondrial DNA mutations at nucleotide 8993. Am J Hum Genet. 1999;65:474-82.

11. The Japan Society of Obstetrics and Gynecology. Policy statement on prenatal genetic testing and prenatal diagnosis. 2018. http://www.jsog.or.jp/modules/statement/index.php?content_id=33 (in Japanese). Accessed 05 July 2020.

12. Kondo H, Tanda K, Tabata C, Hayashi K, Kihara M, Kizaki Z, et al. Leigh syndrome with Fukuyama congenital muscular dystrophy: a case report. Brain Dev. 2014;36:730-3.

13. El-Hattab AW, Wang J, Dai H, Almannai M, Staufner C, Alfadhel M, et al. MPV17-related mitochondrial DNA maintenance defect: new cases and review of clinical, biochemical, and molecular aspects. Hum Mutat. 2018;39:461-70.

14. Kohda M, Tokuzawa Y, Kishita Y, Nyuzuki H, Moriyama Y, Mizuno Y, et al. A comprehensive genomic analysis reveals the genetic landscape of mitochondrial respiratory chain complex deficiencies. PLoS Genet. 2016;12:e1005679.

15. Shimura M, Kuranobu N, Ogawa-Tominaga M, Akiyama N, Sugiyama Y, Ebihara T, et al. Clinical and molecular basis of hepatocerebral mitochondrial DNA depletion syndrome in Japan: evaluation of outcomes after liver transplantation. Preprint at doi:10.21203/rs.3.rs-17666/v2 (2020)

16. Kim J, Kang E, Kim Y, Kim JM, Lee BH, Murayama K, et al. MPV17 mutations in patients with hepatocerebral mitochondrial DNA depletion syndrome. Mol Genet Metab Rep. 2016;8:74-6.

17. Niida Y, Ozaki M, Shimizu M, Ueno K, Tanaka T. Classification of uniparental isodisomy patterns that cause autosomal recessive disorders: proposed mechanisms of different proportions and parental origin in each pattern. Cytogenet Genome Res. 2018;154:137-46.

18. Vento JM, Pappa B: Genetic counseling in mitochondrial disease. Neurotherapeutics. 2013;10:243-50.

19. Wilson RD, Gagnon A, Audibert F, Campagnolo C, Carroll J, Brock JA, et al. Prenatal diagnosis procedures and techniques to obtain a diagnostic fetal specimen or tissue: maternal and fetal risks and benefits. J Obstet Gynaecol Can. 2015;37:656-68. 
20. Wulff CB, Gerds TA, Rode L, Ekelund CK, Petersen OB, Tabor A, Danish Fetal Medicine Study Group. Risk of fetal loss associated with invasive testing following combined first-trimester screening for Down syndrome: a national cohort of 147,987 singleton pregnancies. Ultrasound Obstet Gynecol. 2016;47:38-44.

21. Sato K, Sueoka K, lino K, Senba H, Suzuki M, Mizuguchi Y, et al. Current status of preimplantation genetic diagnosis in Japan. Bioinformation. $2015 ; 11: 254-60$

22. Marchington D, Malik S, Banerjee A, Turner K, Samuels D, Macaulay V, et al. Information for genetic management of mtDNA disease: sampling pathogenic mtDNA mutants in the human germline and in placenta. J Med Genet. 2010;47:257-61.

23. Sallevelt SCEH, de Die-Smulders CEM, Hendrickx ATM, Hellebrekers DMEI, de Coo IFM, Alston CL, et al. De novo mtDNA point mutations are common and have a low recurrence risk. J Med Gent. 2017;54:73-83.

24. Stenton SL, Prokisch H. Advancing genomic approaches to the molecular diagnosis of mitochondrial disease. Essays Biochem. 2018;62:399-408.

\section{Tables}

Table 1: Clinical characteristics of 13 probands

\begin{tabular}{|c|c|c|c|c|c|c|c|c|c|c|}
\hline $\begin{array}{l}\text { Pt } \\
\text { No. }\end{array}$ & $\begin{array}{l}\text { Family } \\
\text { No. }\end{array}$ & Sex & Mutation & $\begin{array}{l}\text { Clinical } \\
\text { diagnosis }\end{array}$ & $\begin{array}{l}\text { Consanguinity, } \\
\text { family history }\end{array}$ & Initial symptom & Onset & Status & Clinical picture & $\begin{array}{l}\text { Aff } \\
\text { con }\end{array}$ \\
\hline 314 & $\# 1$ & Female & $\begin{array}{l}B O L A 3 \\
\text { c. } 287 A>G / c .287 A>G \rrbracket\end{array}$ & $\mathrm{CM}$ & $(-)$ & Vomiting & $2 \mathrm{~m}$ & $\begin{array}{l}\text { Dead } \\
(5 \mathrm{~m})\end{array}$ & 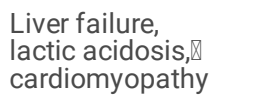 & $\mathrm{Cl}+$ \\
\hline 268 & \#2 & Female & $\begin{array}{l}B O L A 3 \\
\text { c. } 287 A>G / c .287 A>G\end{array}$ & LIMD & $(-)$ & Feeding difficulty & $24 \mathrm{~d}$ & $\begin{array}{l}\text { Dead } \\
(11 \mathrm{~m})\end{array}$ & Apnea, epilepsy & $\mathrm{Cl}+$ \\
\hline 286 & \#3 & Male & $\begin{array}{l}B O L A 3 \\
\text { c. } 287 A>G / c .287 A>G\end{array}$ & $\begin{array}{l}\text { LD } \\
+ \\
\text { FCMD }\end{array}$ & $\begin{array}{l}(-) \\
\text { EB died } \\
\text { at } 4 \mathrm{~m} \text {. }\end{array}$ & $\begin{array}{l}\text { Lactic acidosis, } \\
\text { hyperglycemia, } \\
\text { elevated } \\
\text { creatine kinase }\end{array}$ & $17 d$ & $\begin{array}{l}\text { Dead } \\
(17 \mathrm{~m})\end{array}$ & $\begin{array}{l}\text { Muscle weakness, } \\
\text { hypotonia, } \\
\text { cardiomyopathy }\end{array}$ & $\mathrm{Cl}+$ \\
\hline 25 & $\# 4$ & Female & $\begin{array}{l}A C A D 9 \\
\text { C. } 1766-2 A>G / \\
\text { c. } 811 \mathrm{~T}>\mathrm{G}\end{array}$ & NLIMD & $\begin{array}{l}(-) \\
\text { ES died at } 6 \\
\mathrm{~m} .\end{array}$ & Myotonia & $5 \mathrm{~m}$ & $\begin{array}{l}\text { Dead } \\
(1 \mathrm{y} 1 \mathrm{~m})\end{array}$ & $\begin{array}{l}\text { Hypertrophic } \\
\text { cardiomyopathy, } \\
\text { lactic acidosis }\end{array}$ & $\mathrm{Cl}$ \\
\hline 512 & \#5 & Female & $\begin{array}{l}\text { NDUFAF6 } \\
\text { c. } 805 \mathrm{C}>\mathrm{G} / \mathrm{c} .226 \mathrm{~T}>\mathrm{C}\end{array}$ & LD & $(-)$ & Regression & $7 \mathrm{~m}$ & $\begin{array}{l}\text { Dead } \\
(5 \mathrm{y})\end{array}$ & Lactic acidosis & $\mathrm{Cl}$ \\
\hline 622 & \#6 & Male & $\begin{array}{l}\text { TUFMV } \\
\text { c.440T>A/c.162delC }\end{array}$ & LIMD & $\begin{array}{l}\text { Unknown } \\
\text { YB died } \\
\text { at } 20 \mathrm{~d} \text {. }\end{array}$ & ELBW infant & $0 \mathrm{~d}$ & $\begin{array}{l}\text { Dead } \\
(0 \mathrm{~m})\end{array}$ & $\begin{array}{l}\text { Lactic acidosis, } \\
\text { apnea }\end{array}$ & $\mathrm{Cl}+$ \\
\hline 1401 & $\# 7$ & Male & $\begin{array}{l}T A Z \\
\text { c. } 367 \mathrm{C}>\mathrm{T}\end{array}$ & $\mathrm{CM}$ & $(-)$ & $\begin{array}{l}\text { Cyanosis, } \\
\text { respiratory failure }\end{array}$ & $8 \mathrm{~m}$ & $\begin{array}{l}\text { Dead } \\
(8 \mathrm{~m})\end{array}$ & Cardiomyopathy & $\mathrm{Cl}+$ \\
\hline 346 & \#8 & Female & $\begin{array}{l}E C H S 1 \\
\text { c. } 176 \mathrm{~A}>\mathrm{G} / \mathrm{c} .476 \mathrm{~A}>\mathrm{G}\end{array}$ & LIMD & $\stackrel{(-)}{\text { ES died at } 1 \mathrm{~d} .}$ & Lactic acidosis & $0 \mathrm{~d}$ & $\begin{array}{l}\text { Dead } \\
(4 \mathrm{~m})\end{array}$ & $\begin{array}{l}\text { Lactic acidosis, } \\
\text { metabolic acidosis }\end{array}$ & $\mathrm{Cl}$ \\
\hline 1244 & $\# 9$ & Male & $\begin{array}{l}\text { MPV17 } \\
\text { c.451_452insC/ } \\
\text { c.451_452insC }\end{array}$ & HD & $(-)$ & Poor weight gain & $1 \mathrm{~m}$ & $\begin{array}{l}\text { Dead } \\
(10 \mathrm{~m})\end{array}$ & $\begin{array}{l}\text { Hyperbilirubinemia, } \\
\text { MTDPS }\end{array}$ & $\mathrm{Cl}+$ \\
\hline 2206 & \#10 & Female & $\begin{array}{l}\text { RARS2 } \\
\text { c. } 944 \mathrm{G}>\mathrm{C} / \mathrm{c} .944 \mathrm{G}>\mathrm{C}\end{array}$ & NLIMD & $(-)$ & Regression & $2 d$ & $\begin{array}{l}\text { Alive } \\
(1 \mathrm{y})\end{array}$ & $\begin{array}{l}\text { Cardiomyopathy, } \\
\text { lactic acidosis }\end{array}$ & NA \\
\hline 1943 & $\# 11$ & Male & $\begin{array}{l}\text { MPV17 } \\
\text { c.451insC/c.308_310del }\end{array}$ & $\mathrm{HD}$ & $(-)$ & RDS & $0 \mathrm{~d}$ & $\begin{array}{l}\text { Alive } \\
(3 \mathrm{y})\end{array}$ & $\begin{array}{l}\text { Hypoglycenia, } \\
\text { MTDPS }\end{array}$ & NA \\
\hline 2307 & \#12 & Male & $\begin{array}{l}B O L A 3 \\
\text { c. } 287 A>G / c .287 A>G \\
\text { (Maternal UPD) }\end{array}$ & $\mathrm{CM}$ & $(-)$ & Unconsciousness & $4 \mathrm{~m}$ & $\begin{array}{l}\text { Dead } \\
(4 \mathrm{~m})\end{array}$ & $\begin{array}{l}\text { Cardiomyopathy, } \\
\text { hypoclycenia, } \\
\text { hyperlactemia }\end{array}$ & $\mathrm{Cl}+$ \\
\hline 2313 & $\# 13$ & Male & $\begin{array}{l}\text { BOLA3 } \\
\text { c. } 287 \mathrm{~A}>\mathrm{G} / \mathrm{c} .136 \mathrm{C}>\mathrm{T}\end{array}$ & $\mathrm{CM}$ & $(-)$ & Regression & $5 \mathrm{~m}$ & $\begin{array}{l}\text { Dead } \\
(6 \mathrm{~m})\end{array}$ & $\begin{array}{l}\text { Hypotonia, } \\
\text { cardiomyopathy }\end{array}$ & NA \\
\hline
\end{tabular}

CM, cardiomyopathy; LIMD, lethal infantile mitochondrial disease; NLIMD, nonlethal infantile mitochondrial disease; LD, Leigh disease; FCMD, Fukuyama congenital muscular dystrophy; HD, hepatic disease; MTDPS, mitochondrial DNA depletion syndrome; EB, elder brother; $E S$, elder sister; YB, younger brother; $n$ month(s); d, day(s); y, year(s); ELBW infant, extremely low birth weight infant; RDS, respiratory distress syndrome; Affected complex, affected mitochondrial respiratory chain complex; NA, not available 


\section{6 cases underwent prenatal diagnosis}

CVS: 9 cases, AC: 6 cases, CVS+AC: 1 case

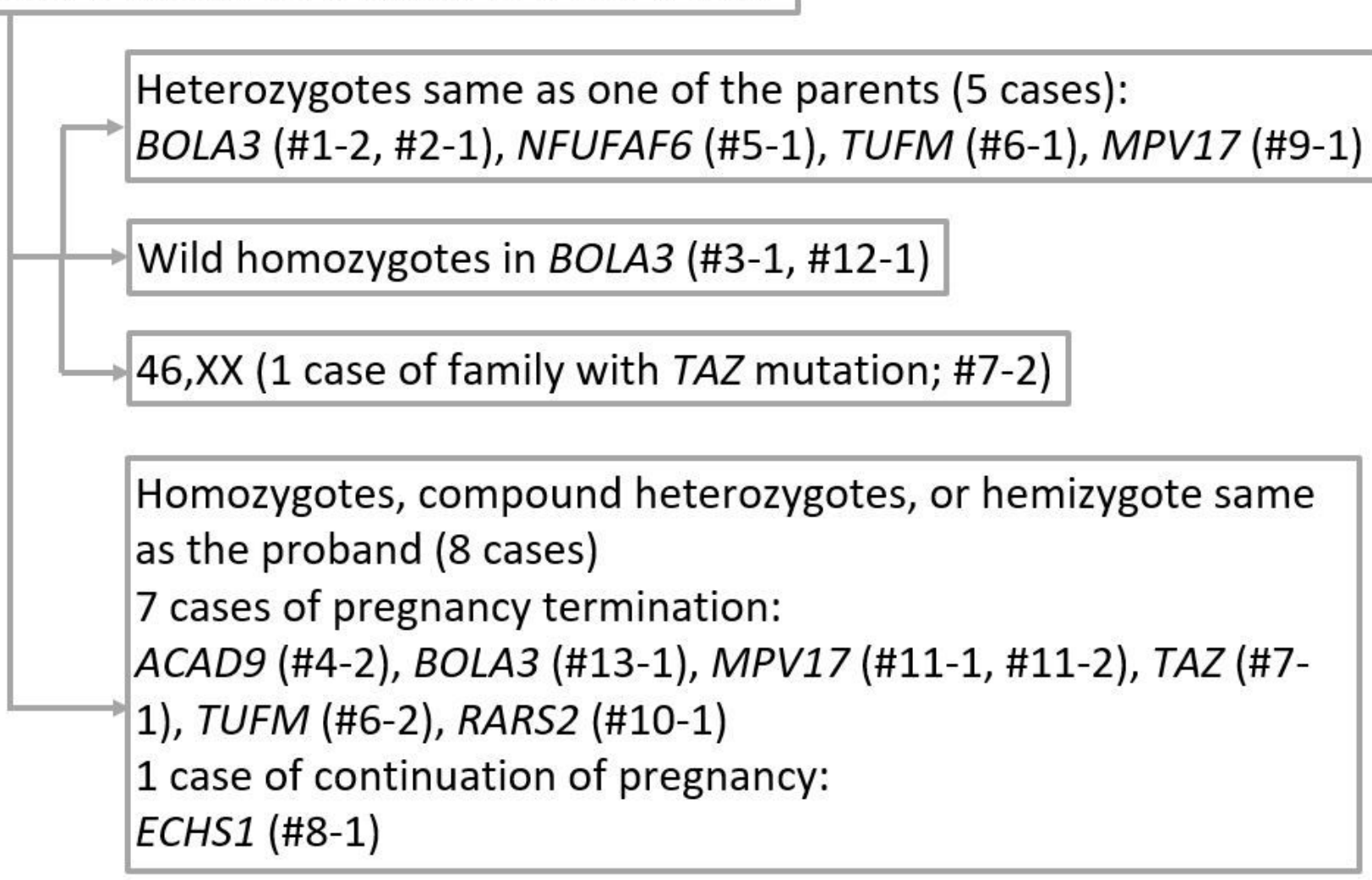

Figure 1

Results of prenatal testing. We conducted prenatal testing for 16 cases. Of them, eight fetuses were not affected and the pregnancies were continued. The other eight fetuses had the same pathogenic variants as the proband. One family decided to continue the pregnancy and the other seven opted for the termination of pregnancy. CVS, chorionic villus sampling; $\mathrm{AC}$, amniocentesis. 


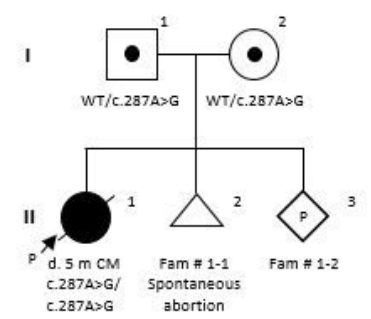

(a) Fam \#1: BOLA3

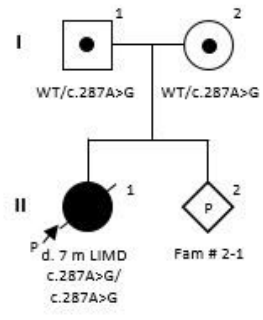

(b) Fam \#2: BOLA3

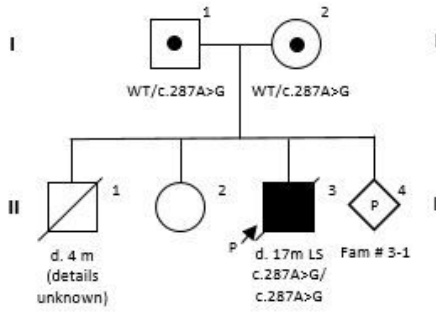

(c) Fam \#3: BOLA3

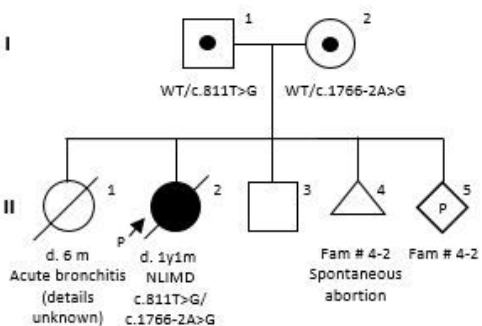

(d) Fam \#4: ACAD9

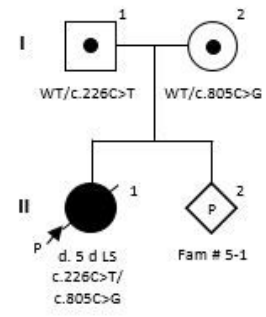

(e) Fam \#5: NDUFAF6

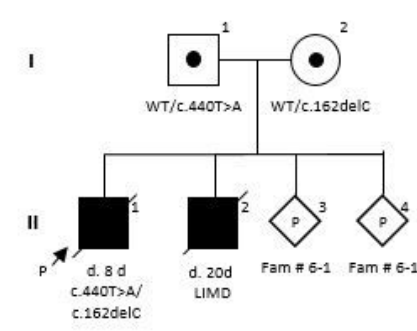

(f) Fam \#6: TUFM

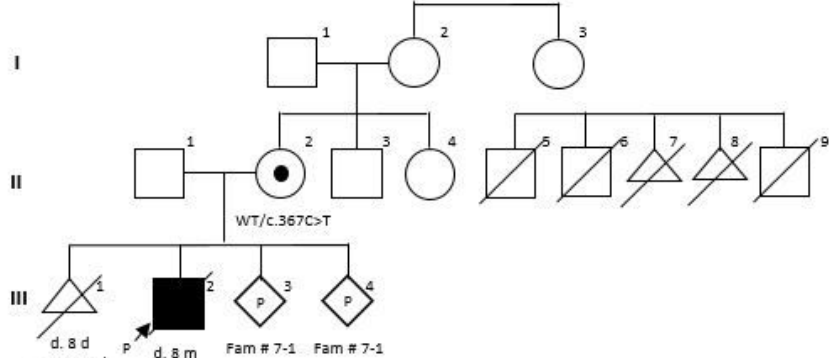

(g) Fam \#7: TAZ

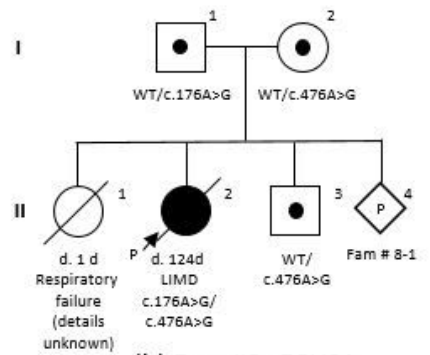

(h) Fam \#8: ECHS1

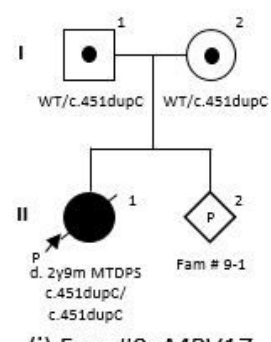

(i) Fam \#9: MPV17

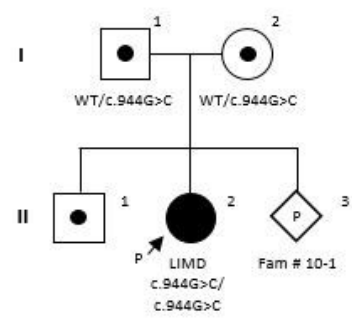

(j) Fam \#10: RARS2

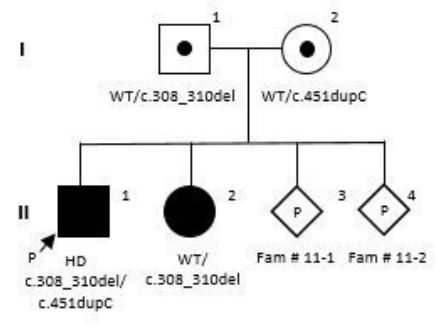

(k) Fam \#11: MPV17

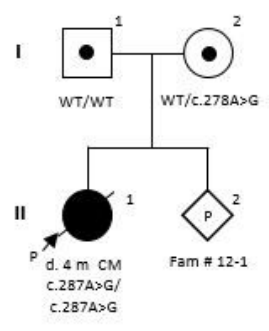

(I) Fam \#12: BOLA3

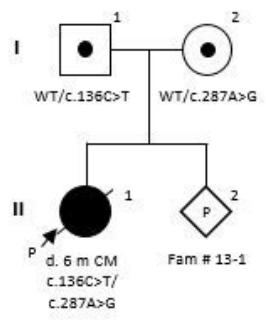

(m) Fam \#13: BOLA3

\section{Figure 2}

Family tree of 13 probands. One family had X chromosome-linked gene mutation; the other 12 families had autosomal recessive gene mutations. In our cohort, there was no consanguineous couple. Fam, family; CM, cardiomyopathy; LIMD, lethal infantile mitochondrial disease; NLIMD, non-lethal infantile mitochondrial disease; LS, Leigh syndrome; HD, hepatic disease; MTDPS, mitochondrial DNA depletion syndrome; WT, wild type; m, month; d, day; y, year. 